\title{
The greenhouse gas inventory of a local urban transport: the case of the municipality of Siena (Italy)
}

\author{
A. C. I. Pizzigallo, R. M. Pulselli \& N. Marchettini \\ Department of Chemical and Biosystems Sciences, University of Siena, \\ Italy
}

\begin{abstract}
Up to now, urban mobility demand keeps increasing at a great rate and it is satisfied mainly by road transportation mode. Road urban transport, especially private, causes the rise of greenhouse gas concentrations inside cities as a result of increasing commuting. For this reason, local public administrations focus their efforts on more sustainable management of urban transport, both private and public, in order to improve the air quality.

The aim of this paper is to assess the greenhouse gas emissions related to urban vehicular traffic in the municipality of Siena (Italy) by way of the Greenhouse Gas Inventory. This methodology is able to quantify greenhouse gas sources and sinks at a local level following the IPCC Guidelines for National Greenhouse Gas Inventories. This powerful tool enhances the knowledge of local administrative authorities in planning and managing a local territorial system. We conducted our analysis with data from the years 1999 and 2000.

Starting from the Greenhouse Gas Inventory of the energy sector of Siena, we can quantify the share of responsibility of greenhouse gas emissions related to urban transport; results show that this share is about $41 \%$ of the total emissions of Siena. Careful consideration will be given to commuting to work and school, in order to provide valuable suggestions to the policy-makers to enforce a more sustainable management of public and private transport at an urban level.

Keywords: Greenhouse Gas Inventory, environmental sustainability, public and private transport system, urban mobility.
\end{abstract}




\section{Introduction}

Emissions of greenhouse gases in the road urban transport sector are steadily increasing. Improvements within the energy efficiency of different means of transport and the introduction of renewable fuels are not sufficient to offset the growth of transport volumes, especially the private one. Therefore, additional policy initiatives and instruments are needed in order to make a major integration between the transport sector and the environmental quality of cities.

Transport is responsible for $21 \%$ of the total greenhouse gas (GHG) emissions in EU-15 (excluding international aviation and maritime transport). During the 1990s, emissions from domestic transport increased by approximately $26 \%$. Even with all planned reduction measures included transport, GHG emissions are projected to grow slightly [1].

During the period 1990-2000, the passenger transport demand in Italy was increased constantly (23\%): it was mainly satisfied by private transport $(82 \%)$, especially in urban systems [2]; indeed, urban mobility demand is satisfied mainly by cars. The demand for mobility inside cities is focused mainly on commuting to school and work, that often is not supported by the right supply of public transport services. This situation entails traffic congestion inside the main roads close to the inner cities, an increase of noise and atmospheric pollution, and a worse quality of life for residents.

Because of its high reliance on the use of non-renewable fossil fuels, urban transport is the major contributor to greenhouse gas emissions $\left(\mathrm{CO}_{2}, \mathrm{CH}_{4}\right.$ and $\mathrm{N}_{2} \mathrm{O}$ ). Other pollutants, such as $\mathrm{NO}_{\mathrm{x}}$ (nitrogen oxides), $\mathrm{SO}_{\mathrm{x}}$ (sulphur oxides), although they are not included in global warming potential-weighted greenhouse gas emission totals, are reported in greenhouse gas inventories, because these pollutants are typical of road transportation.

The aim of this paper is to assess the greenhouse gas emissions related to urban vehicular traffic of the municipality of Siena (Italy) by way of the Greenhouse Gas Inventory. The fundamental methodologies for estimating greenhouse gas emissions from road vehicles follow the 2006 IPCC Guidelines [3]. Emissions of $\mathrm{CO}_{2}, \mathrm{CH}_{4}, \mathrm{~N}_{2} \mathrm{O}, \mathrm{NO}_{\mathrm{x}}$ and $\mathrm{SO}_{\mathrm{x}}$ are estimated from each fuel consumed (represented by fuel sold within the municipality territory as suggested by the geographical approach). This study is part of a more comprehensive multi-year project, called SPIn-Eco. This Project is a research (2001-2004) project aiming to complete a sustainability assessment of the territory of the Province of Siena through the integration of different methods [4]. Among these methodologies such as Emergy Evaluation, Ecological Footprint, etc., the Province of Siena and its municipalities have been studied also by the Greenhouse Gas Inventory [5]; with this method, we were able to quantify the level of global emissions of each municipality of the whole Province, included the municipality of Siena [6].

Results highlight that the transport sector is the major contributor of pollutants in the atmosphere. This is due especially to the high rate of car ownership in Siena with respect to the Italian average one, and poor connections of public transport among suburbs. Moreover, this study suggests that $30 \%$ of 
emissions are closely related to the commuters inside the municipality of Siena. This result is due to the high concentration of workplaces and schools inside the city centre, that determine road congestion close to it.

This discussion is focused on the increasing interest in alleviating congestion on the road transport network, thereby improving economic productivity (by reducing the amount of productive employee time spent sitting in traffic), reducing air pollution, particularly $\mathrm{CO}_{2}$ emissions, lessening noise impacts, and making more efficient and effective use of the road network. At the end of the paper are listed some possible ways to improve the quality of the road network, using both private and public transport, in order to satisfy the high demand for mobility that is only sustained especially by cars. The paper suggests that a better way to make possible the decrease in road congestion is focusing attention on the improvements of accessibility of public transport to give a more sustainable travel network and to supply residents' needs.

\section{Materials and methods}

\subsection{Siena urban transport}

The territorial system of Siena is about $118.71 \mathrm{Km}^{2}$ with a population density of 456 inhab. $/ \mathrm{Km}^{2}$ [7]. The total length of the urban road network of the municipality of Siena is equal to $147.3 \mathrm{Km}$.

Up until 2000, Siena has a high vehicle density (1.08 v./inhab.) with respect the Italian average value $(0.75 \mathrm{v}$./inhab.) and the vehicle numbers are composed of about 58,985 means of transport, both private and public, subdivided as follows: 42,164 cars, 8,590 trucks (heavy and light), 288 buses and 6,439 other means of transport (scooters, special trucks, etc.) [8]. It was estimated that fuels sold to move all vehicles are about $47,495 \mathrm{t}$ of which $58 \%$ of gasoline, $41 \%$ diesel and 1\% Liquefied Petroleum Gases (LPG) [9]; up until 2000, in Siena there was no natural gas-powered vehicles.

Although, the local administration always looks out for environmental care of its territorial system, in the last decade there was an unrelenting increase of greenhouse gas emissions inside the city centre. The making up of the first Limited Traffic Zone (LTZ) in Italy (1960) has not been enough to clamp down the weighty increase of people that choose cars to get round the urban centre; even so, the total number of vehicles (especially cars) has kept increasing at a great rate. This is due to four main reasons: 1) the hill territory not very suitable for a means of transporting more 'environmentally-friendly', e.g. bikes; 2) the residents' migration from the city centre to the less noisy suburbs or, even, to the rural areas; 3) The overstay of the most workplaces and schools inside the LTZ or very close to the LTZ; 4) the undiminished decrease of public transport utilization.

These four load factors of the quality of Siena urban transport have determined the need for commuting, especially by car. Commuting is defined as the process of travelling between a place of residence and a place of work or school. For instance, students who are enrolled at a college or university but who 
live off-campus are also typically referred to as commuters. Commuting is largely a phenomenon which exists in industrialised societies, where access to modern modes of travel, especially car, has enabled people to live far from their workplace. The advent of modern commuting has had a large impact on life. It has allowed cities to expand to sizes which were previously not practical, and it has led to the proliferation of the suburbs. Commuting, especially in the absence of car-pooling, car-sharing or an efficient urban public transport network, is often regarded as a major contributing factor to traffic congestion and, therefore, as a worse of air quality conditions. Commuters (to school or job) in Siena are equal to 24,906 inhabitants ( $45 \%$ of the total population) of which 20,584 use private means of transporting and the $51 \%$ prefer to commute alone with a car (about 10,694).

\subsection{The 2006 IPCC methodology}

The IPCC method [3] is applied to the municipality of Siena situated in Tuscany (central Italy). The 2006 IPCC Guidelines for National Greenhouse Gas Inventories updates the Revised 1996 Guidelines to provide international agreed methodologies to estimate greenhouse gas inventories following the United Nations Framework Convention on Climate Change (UNFCCC). Greenhouse gas emission and removal estimates are divided into main sectors, which are groupings of related processes, sources and sinks: 1) Energy; 2) Industrial Processes; 3) Agriculture, Forestry and other Land Use; 4) Waste; 5) Other (e.g. indirect emissions from nitrogen deposition from non-agriculture sources).

In order to analyse emissions from road urban transport of the municipality of Siena, we focus our attention on mobile combustion of fossil fuels related to the energy sector (IPCC, Volume 2, Energy) [3]. We conducted our analysis with data from the years 1999 and 2000. The mobile source category Road Transportation includes all types of light-duty vehicles such as cars, light trucks, and heavy trucks, buses, motorcycles. Estimated emissions from road transport are based on fuel sold within the territorial system of Siena (Tier 1). Fuel sold to the off-road transportation such as mobile machinery used within the agriculture, forestry, industry, and sectors, such as airport ground support equipment, and also civil aviation are not considered inside the total emissions of the transport sector, because they are not perfectly linked to the urban transport of Siena.

We estimate the direct greenhouse gas emissions of carbon dioxide $\left(\mathrm{CO}_{2}\right)$, methane $\left(\mathrm{CH}_{4}\right)$ and nitrous oxide $\left(\mathrm{N}_{2} \mathrm{O}\right)$ from the combustion of gasoline, diesel and LPG; emissions from $\mathrm{NO}_{\mathrm{x}}$ and $\mathrm{SO}_{\mathrm{x}}$, although they are not included in global warming potential-weighted greenhouse gas emissions totals, are reported in this inventory, because road transportation is the major source of these precursors.

In order to understand the weight of emissions, deriving from fuel combustion by cars in commuting, on the total emissions related to Siena vehicular numbers, we have followed the 2006 IPCC Guidelines that provide an alternative way to estimate fuel consumption, i.e. by distance travelled by vehicles. This alternative approach is suggested by IPCC in order to consider only the on-road fuel use. To apply this method to the commuters of Siena that use cars, it is necessary to know the number and the type of vehicles, the average fuel consumption and the 
distance travelled. The Italian National Statistic Bureau (ISTAT) collects this kind of data divided per type of vehicle and type of fuel; moreover, the time needed by commuters (to work and school) to reach their workplace and come back home [10] is also available.

Following the IPCC, the next formula, eqn (1), is useful to validate fuel consumption related to cars in commuting:

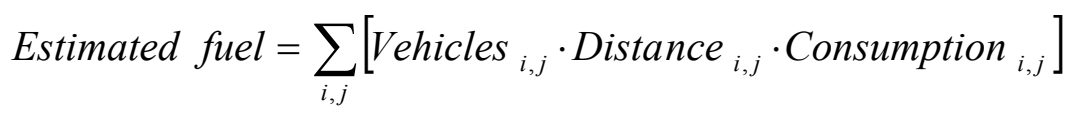

where:

estimated fuel are the total estimated fuel use estimated from distance travelled data; vehicles are equal to the number of vehicles of type $i$ and using fuel $j$; Distance is equal to the annual kilometres travelled by vehicle of type $i$ and using fuel $\mathrm{j}$; consumption is equal to the average fuel consumption by vehicles of type $\mathrm{i}$ and using fuel $\mathrm{j}$.

\section{Results and discussion}

Following the Tier 1 presented in the 2006 IPCC Guidelines for estimating emissions from fossil fuel combustion, we have assessed the direct and indirect Gigagrams of equivalent $\mathrm{CO}_{2}\left(\mathrm{Gg}\right.$ eq. $\left.\mathrm{CO}_{2}\right)$ that enter the municipality. Starting from the total emissions of the energy sector estimated for this territory, the major contributor to the total amount of emissions is the transport sector (Table 1).

Table 1: $\quad$ The Greenhouse Gas Inventory of the energy sector of Siena.

\begin{tabular}{|l|c|}
\hline & Gg eq.CO \\
\hline Electricity & 119.85 \\
\hline Transport & 148.51 \\
\hline Heating & 95.81 \\
\hline Total & 364.17 \\
\hline
\end{tabular}

From table 1, we can see that transport sector has the higher amount of equivalent $\mathrm{CO}_{2}$. This value is lower than the Italian one (about $61 \%$ ) [11].

Table 2 shows the amount of $\mathrm{Gg}$ eq. $\mathrm{CO}_{2}$ related to the vehicles of Siena. The total amount of $\mathrm{Gg}$ eq. $\mathrm{CO}_{2}$ is not equal to the total amount of $\mathrm{Gg}$ eq. $\mathrm{CO}_{2}$ related to the transport system in table 1 , because a share of these emissions are referred to railways that are not accounted within urban transport.

Table 2 underlines that the major contributor to traffic emissions within the city centre of Siena is related to cars. The second more important contributor is related to the light-duty trucks, certainly more suitable for a cramped urban centre like Siena.

Figure 2 shows all emissions (in percentage) for all vehicles types to the total amount of emissions in Siena urban transport. 


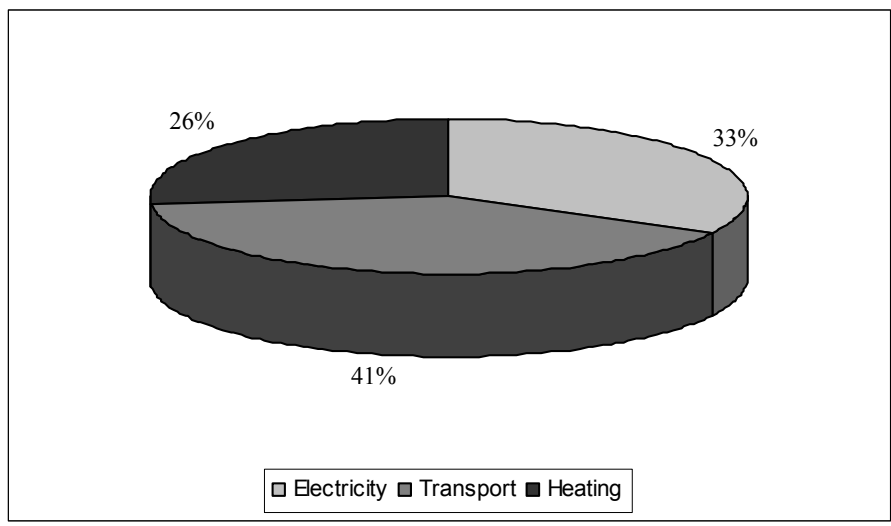

Figure 1: Equivalent $\mathrm{CO}_{2}$ emissions of the municipality of Siena in percentage.

Table 2: $\quad$ Emissions of vehicles of Siena (year 2000).

\begin{tabular}{|l|c|}
\hline \multicolumn{1}{|c|}{ Vehicles } & Gg eq. $\mathbf{C O}_{\mathbf{2}}$ \\
\hline Cars & 99.53 \\
\hline Light-duty trucks & 29.27 \\
\hline Heavy-duty trucks and buses & 5.91 \\
\hline Motorcycles & 11.33 \\
\hline Total & 146.04 \\
\hline
\end{tabular}

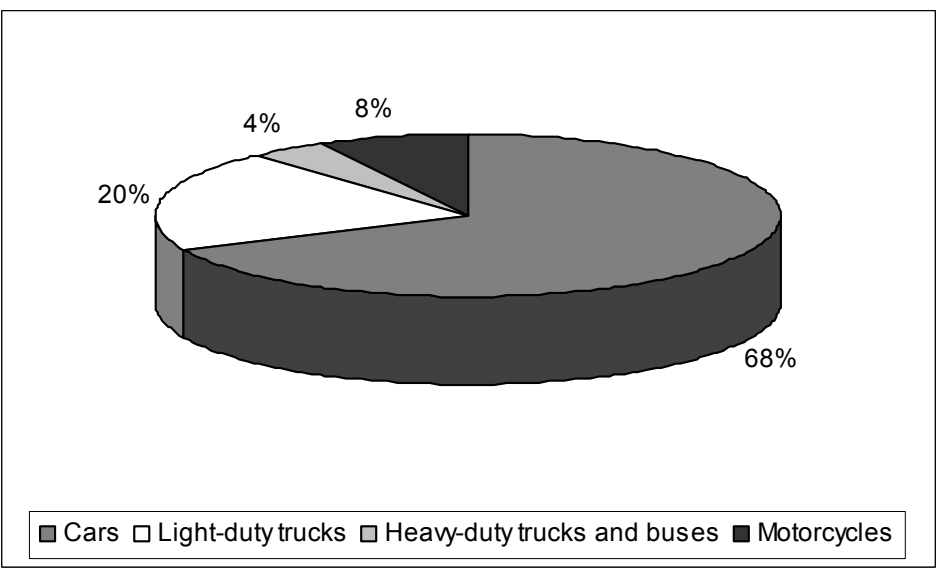

Figure 2: Emissions of vehicles of the municipality of Siena as a percentage. 
Road transportation is also the main source of $\mathrm{NO}_{\mathrm{x}}$ and $\mathrm{SO}_{\mathrm{x}}$ as precursors. Although they are not considered in the global warming potential, we have reported the results related to these two kinds of pollutants.

Table 3 shows results for $\mathrm{NO}_{\mathrm{x}}$ and $\mathrm{SO}_{\mathrm{x}}$ expressed in $\mathrm{kg}$. Emissions of sulphur oxides $\left(\mathrm{SO}_{\mathrm{x}}\right)$ are primarily related to the sulphur content of the fuel, although some sulphur can be retained in the ash. However, the major contributor to the air pollution is $\mathrm{NO}_{\mathrm{x}}$ that is an order of magnitude bigger than $\mathrm{SO}_{\mathrm{x}}$.

Table 3: $\quad$ Emissions of $\mathrm{NO}_{\mathrm{x}}$, and $\mathrm{SO}_{\mathrm{x}}$ in Siena (expressed in $\mathrm{kg}-$ year 2000).

\begin{tabular}{|l|r|r|}
\hline \multicolumn{1}{|c|}{ Vehicles } & \multicolumn{1}{c|}{ NO $_{\mathbf{x}}$} & \multicolumn{1}{c|}{ SO $_{\mathbf{x}}$} \\
\hline Cars & $951,851.37$ & $75,819.72$ \\
\hline Light-duty trucks & $312,856.79$ & $50,052.78$ \\
\hline Heavy-duty trucks and bus es & $66,579.99$ & $11,682.06$ \\
\hline Motorcycles & $96,062.44$ & $7,723.35$ \\
\hline TOTAL & $1,427,350.57$ & $145,277.91$ \\
\hline
\end{tabular}

Table 4: $\quad$ Emissions of car commuters divided by type of fuel.

\begin{tabular}{|l|r|}
\hline \multicolumn{1}{|c|}{ Fuel type } & Gg eq. CO2 \\
\hline Petrol Gas oline & 40.01 \\
\hline Diesel & 2.46 \\
\hline Liquified Petroleum Gas es & 1.05 \\
\hline TOTAL & 43.53 \\
\hline
\end{tabular}

Table 4 shows the weight of emissions related to commuting in 2000 . In this table only the commuters that travel alone in their cars (about 10,694 commuters) are considered. The distribution of emissions among the different fuels gives the framework of the share of cars of Siena used by commuters. In fact, residents own more gasoline cars, than diesel cars, whereof most of them are economy cars; which are more comfortable and more suitable for the characteristics of the traffic of Siena.

The total emissions related to cars in commuting represent $30 \%$ of the total emissions of the road urban transport. Moreover, they occur in two periods of the day, namely the morning and evening peak-periods of commuting. This daily situation determines worsening air quality conditions, higher energy consumption to power vehicles, traffic congestion within the main roads close to the city centre, with an increasing demand for car parks, and a huge waste of time that leads to bad economic productivity of employees.

The inner city of Siena contains most workplaces and schools inside itself. Banks, university, offices (both private and public), and schools attract a flurry of commuters everyday. This need to reach a given point by commuters within the Limited Traffic Zone of Siena determines a high waste of time for employees and pupils sitting in traffic, with a consequent worsening in air quality. Public transport, often inadequate and scarcely frequent, is not able to sustain the 
demand for mobility; cars are preferred to buses, and the twofold daily peakperiod of car congestion is the expression of a low sustainability level of urban transport in Siena.

The efforts of the local administration may be focused to provide incentives to commuters, in order to improve the accessibility of the inner city through public transport; improvements of the public transport network (e.g. higher frequency ride, dedicated lanes to public means of transport, higher quality of service) can lead to a higher level of service and comfort. Conversely, experiences from several cities suggest that construction of more high capacity roads can have the unintended effect of reductions in public transport without increasing vehicle speeds or reducing congestion on city roads. Reductions in bus use would result in higher pollution levels and possible increase in traffic congestion.

These suggestions foster new and more efficient ways of moving through and interacting with the city by providing residents with more flexible, convenient travel options. If successful, these strategies as a whole should reduce the amount of depletable resources consumed, and thus represent a step along a path toward sustainability of public urban transport.

\section{Conclusions}

The aim of this paper was to assess the greenhouse gases emissions related to urban vehicular traffic of the municipality of Siena (Italy) by way of the Greenhouse Gas Inventory. The fundamental methodologies for estimating greenhouse gas emissions from road vehicles followed the 2006 IPCC Guidelines. Emissions of $\mathrm{CO}_{2}, \mathrm{CH}_{4}, \mathrm{~N}_{2} \mathrm{O}, \mathrm{NO}_{\mathrm{x}}$ and $\mathrm{SO}_{\mathrm{x}}$ were estimated from each fuel consumed (represented by fuel sold inside Siena as suggested by the geographical approach).

Transport is one of the most significant sources of unsustainability in urban areas. Commuters are car-dependent and local air quality is affected by the immoderate increase of private transport options. Commuting by car represents $30 \%$ of the total amount of greenhouse gases emitted in Siena.

Currently, the combination of a lack integration in public transport systems means that the passenger services offered and the effectiveness of public transport are generally poor. The current public transport network follows a dispersed pattern, characterised especially by low-frequency routes. Significant improvements can be realised through the provision of a rationalised and consolidated public transport network structure, e.g. improving the links among suburbs, and between suburbs and the middle centre. This would lead to a more efficient transport system and enable transport to play a greater role as a catalyst for more effective urban development.

\section{References}

[1] EEA. Greenhouse gas emission trends and projections in Europe 2006. EEA Report No 9/2006. 
[2] APAT. La mobilità in Italia: indicatori su trasporti e ambiente. a cura di Contaldi M., Pignatelli R., Servizio Sviluppo sostenibile e pressioni ambientali, Settore Pressioni ambientali, Roma, 2005.

[3] IPCC. 2006 IPCC Guidelines for National Greenhouse Gas Inventories, Prepared by the National Greenhouse Gas Inventories Programme, Eggleston H. S., Buendia L., Miwa K., Ngara T. and Tanabe K. (eds). Published: IGES, Japan, 2006.

[4] Pulselli, F.M., Ciampalini, F., Leipert, C., Tiezzi, E.,. Integrating methods for the environmental sustainability: the SPIn-Eco Project in the Province of Siena (Italy). Journal of Environmental Management, in press, 2006.

[5] Kneller, M., Fugaro, L., Marchettini N. The greenhouse gas inventory of the Province of Siena, Ecosystems and Sustainable Development IV, Advances in Ecological Sciences, (eds) Tiezzi, E., Brebbia, C.A., Usò, J.L., WIT Press, Southampton, UK, 2003.

[6] Ridolfi, R., Kneller, M., Donati A., Pulselli, R.M. The greenhouse gas balance of the Province of Siena, Journal of Environmental Management, In Press, 2006.

[7] ISTAT. Ricostruzione della popolazione residente per età e sesso nei comuni italiani Anni 1992-2001, Informazioni, n.13, 2006

[8] ACI. Serie storiche sullo sviluppo della motorizzazione e sull'incidentalità stradale in Italia negli anni 1921-2003. Direzione centrale studi e ricerche - Automobile Club Italia, Area statistica, 2005.

[9] Direzione Generale dell'Energia e delle Risorse Minerarie (DGERM) Osservatorio Statistico Energetico. Serie storica delle vendite di benzine, gasoli, olio combustibile, gpl e lubrificanti, Bollettino statistico annuale, 2000.

[10] ISTAT. $14^{\circ}$ censimento della popolazione e delle abitazioni. Direzione centrale della diffusione della cultura e dell'informazione statistica, 2001. Available online at: http://dawinci.istat.it/daWinci/jsp/MD/index.html

[11] Relazione sullo stato dell'Ambiente in Italia, a cura del Ministero dell'Ambiente e della tutela del territorio, 2005. Available online at: http://www2.minambiente.it/ 